\title{
PTFE Energy Absorber of Explosive Initiator under High-g Loading
}

\author{
Wei Liu, Lizhi Wu, Xiaoxia Sun, Ruiqi Shen, Yinghua Ye \\ Nanjing University of Science and Technology, \\ Nanjing, China
}

\begin{abstract}
In order to decrease the damage of the explosive initiator under high-g loading, a PTFE tube was designed as energy absorber and used in the initiator. For this purpose, the split Hopkinson pressure bar was firstly performed to test the dynamic mechanical parameters of PTFE material, which were later applied as input data for LS-DYNA simulation program under airgun high-g loading environment. Finally, the damage of both initiator and PTFE were obtained. Results reveal that yield stress, elasticity modulus, and tangent modulus of PTFE are 18 MPa, 2.25 GPa and 134 MPa, respectively. Due to existence of the PTFE tube, the damage of the explosive initiator decreases, and the damage of the initiator decreases gradually with the increase of thickness of the PTFE tube. As well, the energy change of the PTFE tube with the thickness shows that the most suitable thickness is $0.3 \mathbf{~ m m}$.
\end{abstract}

Keywords-dynamic mechanics; PTFE, high-g loading; explosive initiator

\section{INTRODUCTION}

As initial element of the ammunition, explosive initiator plays a key role in the weapon system. Under high-g loading environment of oblique penetration between bullet and target or explosive dispersion of cluster bomb, the ammunition is subjected to not only axial stress wave but also lateral inertial force, leading to high temperature, high pressure, and large deformation of the ammunition components [1]. One effective approach is to use energy absorbing material to decrease the plastic change of the explosive initiator. PTFE has many advantageous properties, such as high thermal stability, low friction [2], solvent resistant, and good electrical insulation properties, which make it an ideal filler material for a wide variety of applications [3]. As well, PTFE has also been used as energy absorber in explosive initiator due to good plasticity under high-g loading environment.

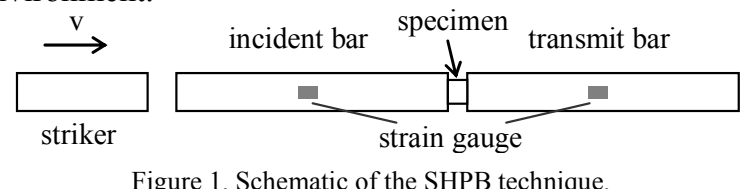

The aim of the present work is primarily to enhance the characteristic of the explosive initiator under high-g loading environment by using the PTFE as energy absorber. For this purpose, dynamic stress-strain characteristic of the PTFE material at different strain rates are firstly performed by using the split Hopkinson pressure bar (SHPB) technique. The basic material parameters for kinematic hardening plasticity model of the PTFE are then obtained. Following, a PTFE tube is designed as an energy absorber to decrease the damage of the explosive initiator under high-g loading. Finally, according to the measured material parameters of PTFE, simulation is performed by LS-DYNA nonlinear explicit dynamic software to show that the PTFE tube can protect the electric plug in the initiator from damaging.

\section{DYNAMIC CHARACTERISTICS OF PTFE}

\section{A. SHPB Setup}

The split Hopkinson pressure bar technique has been widely used by many researchers to study the dynamic mechanics characteristic of a variety of materials, such as concrete [4], memory alloy [5], and even human bone [6] under high strain rate. The system mainly consists of gas gun, a striker, an incident bar, a transmit bar, and other measuring devices, as schematically shown in Figure 1.

Based on one-dimensional wave theory and stress equilibrium assumption, the stress-strain formula of the specimen is as following:

$$
\begin{aligned}
& \dot{\varepsilon}(t)=C\left[\varepsilon_{i}(t)+\varepsilon_{r}(t)-\varepsilon_{t}(t)\right] / L \\
& \varepsilon=2 C / L \int_{0}^{t} \varepsilon_{r}(t) d t \\
& \sigma=E \varepsilon_{r}(t)
\end{aligned}
$$

In Eq. (1), $\dot{\varepsilon}$ is strain rate, $C$ is wave speed of the bar, $L$ is length of the specimen, and $\varepsilon_{i}, \varepsilon_{r}$, and $\varepsilon_{t}$ are strain of incident wave, reflect wave, and transmit wave, respectively. In Eq. (2), $\varepsilon$ is strain of the specimen. In Eq. (3), $\sigma$ is stress of the specimen, and $E$ is elasticity modulus of the bar. The stress-strain of the specimen can be obtained by the above three equations. 


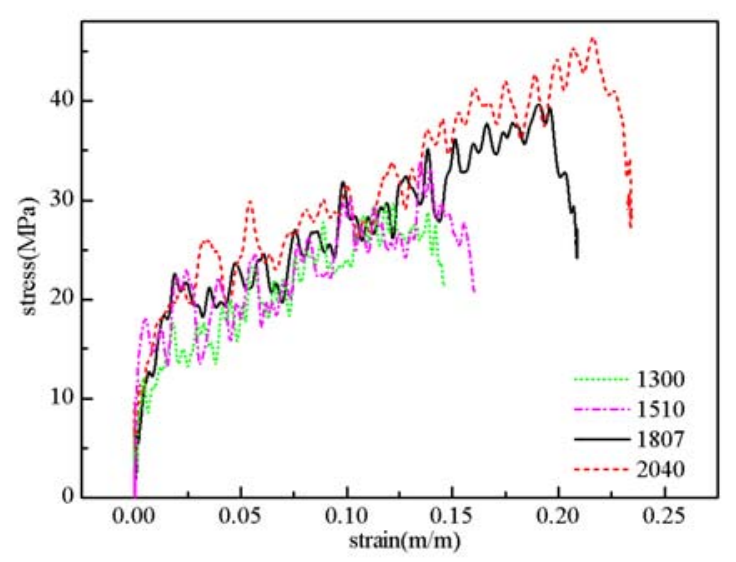

Figure 2. Stress-strain relationship of PTFE.

\section{B. Stress-strain of PTFE}

A $14.5 \mathrm{~mm}$ diameter of Aluminum Hopkinson pressure bar without using pulse shaper was performed to exam the dynamic stress-strain relation of PTFE. Of the bar system, length of striker, incident bar, and transmit bar are 300,1000 , and $800 \mathrm{~mm}$ in turn. The density, elastic modulus, and Poisson's ratio of the bars are $2700 \mathrm{~kg} / \mathrm{m}^{3}$, $72.5 \mathrm{GPa}$ and 0.34 respectively. Dispersion effect was amended by fast Fourier transform (FFT) approach to decrease the high frequency oscillation in the three waves. The stress-strain curves of the PTFE are obtained when the strain rates are $1300,1807,2000$, and $2400 \mathrm{~s}^{-1}$, as shown in Figure 2.

As shown in Figure 2, although the strain rates are different, stress-strain curves of PTFE show no obvious difference. Thus, dynamic characteristic of PTFE material shows strain rate independent. The yield stress of PTFE is about $18 \mathrm{MPa}$ when the nominal strain is $0.8 \%$. On the other hand, dynamic characteristic of PTFE can be regarded as bilinear elastic plastic model, and elasticity modulus and tangent modulus of PTFE are around 2.25 $\mathrm{GPa}$ and $134 \mathrm{MPa}$, respectively, calculated from the stress-strain curve shown in Figure 2.

\section{CAlculation METHOD}

The airgun high-g loading technique, an effective method to test the characteristic of initiator under high-g loading [7], is performed to evaluate the explosive initiator and characterize the performance of PTFE tube as energy absorber.

\section{A. Structure of Explosive Initiator}

In airgun technique, the bullet with conical head is $36.5 \mathrm{~mm}$ in diameter and $107 \mathrm{~mm}$ in length, and the diameter of the head is $30 \mathrm{~mm}$. The steel target is made from $\mathrm{GCr} 15$ steel through quenching process, and its size is $300 \times 240 \times 30 \mathrm{~mm}$.

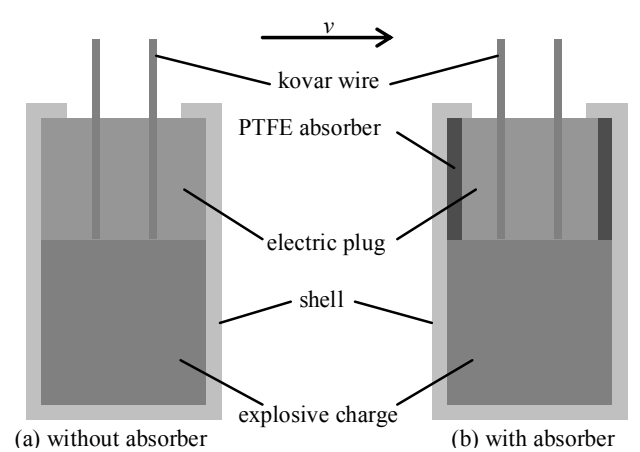

Figure 3. Structure of initiators with and without PTFE energy absorber

The explosive initiator consists of shell, electric plug, and charge. The charge is PETN and $\mathrm{Pb}\left(\mathrm{N}_{3}\right)_{2}$. Total length of initiator is $8 \mathrm{~mm}$, and diameter is $5.1 \mathrm{~mm}$. Length of electric plug is $4 \mathrm{~mm}$ and is made from ceramic. Structure of the original initiator and modified initiator is shown in Figure 3. Diameter of electric plug in original initiator is $4.65 \mathrm{~mm}$, while the diameter of electric plug in modified initiator is $4.25 \mathrm{~mm}$, due to existence of the PTFE tube. In order to acquire the thickness of PTFE tube effect on the energy absorption, thickness of the PTFE tube are $0.1,0.2$, 0.3 and $0.4 \mathrm{~mm}$, and the length are all equal to the length of electric plug.

The initiator is loaded by lateral mode, which means the central axis of the explosive initiator is perpendicular to the central axis of the bullet. The arrow in Figure 3 points to the moving direction of explosive initiator.

\section{B. Calculation Condition and Material Model}

LS-DYNA nonlinear dynamic simulation software [8] is used to calculate the process of the bullet impacting the steel target. Considering the symmetry of the structure and the initial and boundary conditions, a simplified $1 / 2$ model is built. The 8-nodes hexahedral solid element is adopted to mesh the model. In order to save the calculation time and enhance the efficiency, single point integration is used. Hourglass is controlled to avoid the non-physical zero energy mode caused by single point integration. The simulation model and meshed elements are shown in Figure 4.

The contacts between all the components are set as automatic surface to surface contact. Symmetric constraint is loaded on the symmetric section of the model, and the displacement of the outer sections of the steel target is constrained to fix the target. The speed of the bullet is set to $80 \mathrm{~m} / \mathrm{s}$, which is regarded as initial condition.

The explosive charge is described by elastic-plastic hydrodynamic material, and the Lee-Tarver ignition and growth model [9] based on JWL equation of state is used to characterize the pressure of the unreacted explosive charge and reaction products. 


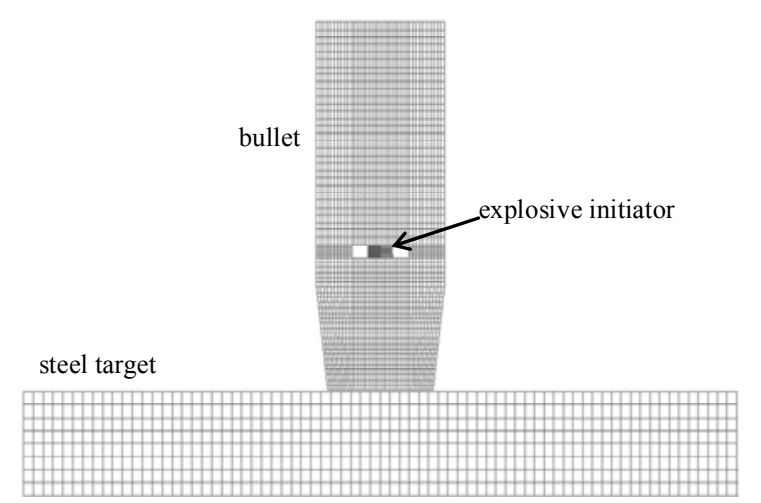

Figure 4. Calculation model and meshed elements.

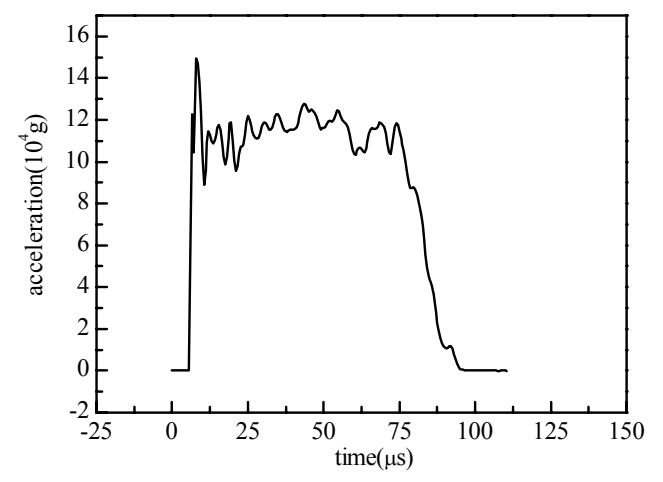

Figure 5. Acceleration-time history of the bullet

The rest components of the initiator are all described as bilinear elastic-plastic model. This model is suited to model isotropic and kinematic hardening plasticity with the option of including rate effects.

\section{RESULTS AND DISCUSSION}

\section{A. High-g Environment}

According to the above model, when the launching speed of the bullet is $80 \mathrm{~m} / \mathrm{s}$, acceleration-time history of bullet is obtained as illustrated in Figure 5. The explosive initiators will be loaded under such high-g environment.

When the bullet impacts the steel target, peak acceleration is about $150,000 \mathrm{~g}$ and the average acceleration is about $117,500 \mathrm{~g}$. The acceleration duration is around $90 \mu \mathrm{s}$. The explosive initiator will be loaded under this condition.

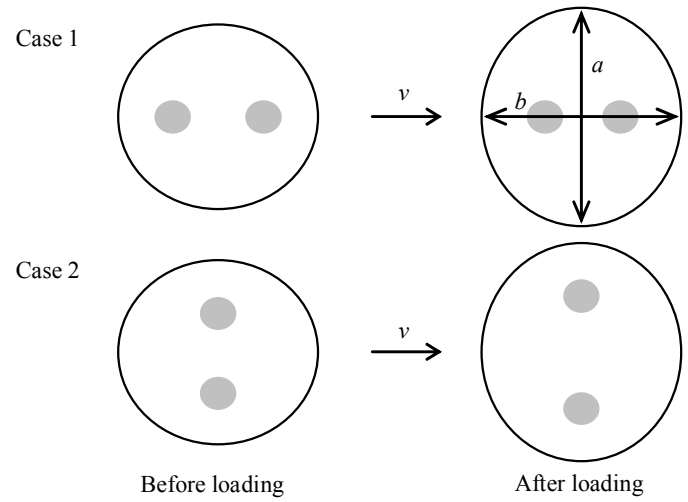

Figure 6. Schematic diagram of electric plug before and after high-g loading.

\section{B. PTFE Effects on Damage of Electric Plug}

Before and after lateral overload, sections of the electric plug in two cases are shown in Figure 6. The arrows point to the moving direction of the initiator. When the explosive initiator is loaded laterally, there are two cases for placing the initiator. In case 1, the connection line between two end surfaces is parallel to moving direction, while the connection line is vertical to the moving direction in case 2 .

Due to high-g loading, sectional shape of the electric plug becomes from circle to oval. Thus, ovality of the section can be defined as damage variable to behave the damage level of the electric plug. Ovality of the section can be regarded as

$$
D r=a / b
$$

where $a$ and $b$ are the long and short diameter of oval section of electric plug.

When PTFE absorbers with different thickness are applied in the initiator, the ovality of electric plugs are calculated and illustrated in Figure 7.

It can be seen from Figure 7 that ovality of the electric plug decreases with the increase of thickness of the PTFE tube, which means the PTFE absorber can obviously decrease the damage of the electric plug. The curve fitting is carried out to obtain the mathematical relationships between ovality and thickness of PTFE absorber. The relationship is

$D r=1.03+0.076 \exp (-3.59 \times T)$

where $T$ is thickness of PTFE absorber. Equation (5) shows exponential relationship between ovality and thickness of absorber. According to Eq. (5), when thickness of absorber $T$ tends to be infinity, the limit of $D r$ is 1.03 , which means there is a critical thickness, beyond which ovality will not change. 


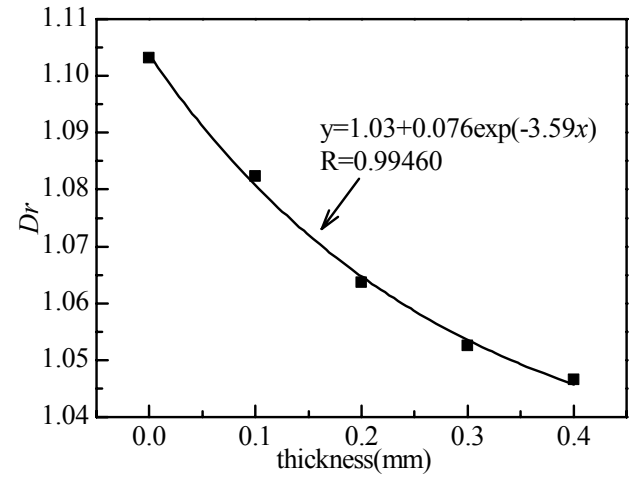

Figure 7. Ovality of electric plug under different thickness of PTFE tube.

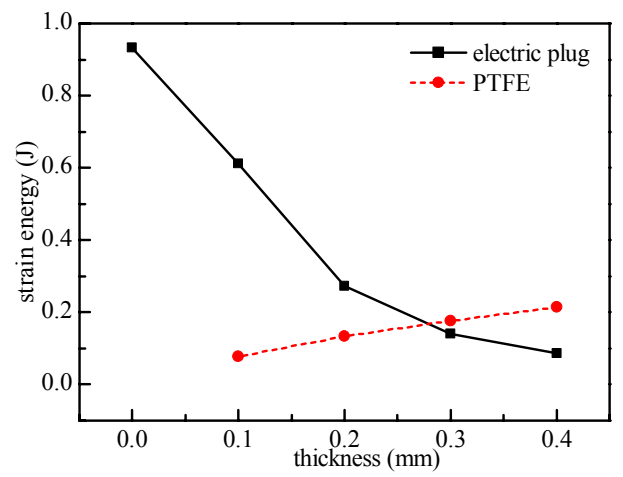

Figure 8. Strain energy of electric plug and PTFE absorber.

\section{Strain Energy of PTFE Absorber}

The energy stored in an object due to deformation is called strain energy, which is generally equal to the amount of energy applied to the object that cased the strain [10]. The general expression for strain energy $U$ is given by [11]

$U=\int_{V} \sigma \varepsilon d V / 2$

where $\sigma$ and $\varepsilon$ are stress resultants and strain, respectively. $V$ is the volume of the object. The strain energy including both elastic and plastic strain energy represents the damage level of the object. The strain energy of electric plug and PTFE absorber is plotted in Figure 8.

As shown in Figure 8, with the increase of thickness of the PTFE absorber, the strain energy of PTFE absorber increases gradually. The strain energy of electric plug drops from $0.932 \mathrm{~J}$ without using PTFE to $0.087 \mathrm{~J}$ when the thickness of PTFE is $0.4 \mathrm{~mm}$, reducing by $91 \%$. This means that the existence of PTFE absorber can obviously cut down the damage of the electric plug, and a thicker PTFE absorber can bring about smaller damage of the electric plug. When the thickness of PTFE is greater than $0.3 \mathrm{~mm}$, strain energy of the electric plug shows no obviously difference. Summarily, $0.3 \mathrm{~mm}$ PTFE absorber is the most suitable to reinforce the explosive initiator.

\section{CONCLUSIONS}

PTFE tube was used as energy absorber in explosive initiator to enhance the anti-overload ability of the explosive initiator under high-g loading. The split Hopkinson pressure bar was firstly performed to test the dynamic mechanical parameters of PTFE material. LSDYNA program was then adopted to simulate the loading process of the initiator with PTFE under airgun high-g loading environment. Finally, the damage of both initiator and PTFE were obtained. Results show that yield stress, elasticity modulus and tangent modulus of PTFE are $18 \mathrm{MPa}, 2.25 \mathrm{Gpa}$, and $134 \mathrm{MPa}$ respectively. The PTFE tube can be effective to decrease the damage of the explosive initiator under high-g loading. Especially, 0.3 $\mathrm{mm}$ is the most suitable thickness for PTFE tube.

\section{REFERENCES}

[1] Zhou Guang-Yu, Hu Shi-Sheng, Pulse-shaping techniques of high-g value acceleration generators. Baozha Yu Chongji, 5(33), pp. 479486, 2013.

[2] Liu Xiao-Xia, An investigation on the friction of oriented polytetrafluoro ethylene (PTFE). Wear, 262(11-12), pp. 14141418, 2007.

[3] J. R. Vail, B.A. Krick, Polytetrafluoro ethylene (PTFE) fiber reinforced polyetheretherketone (PEEK) composites. Wear, (270), pp. 737-741, 2011.

[4] Li Qing-Ming, About the dynamic strength enhancement of concretelike materials in a split Hopkinson pressure bar test. International Journal of Solids and Structures, 40(2), pp. 343-360, 2003.

[5] B. Anatoly, G. Alesia, Functional properties of TiNi shape memory alloy after high strain rate loading. Materials Science Forum. 738739, pp. 326-331, 2013.

[6] C.K. Teja, A. Chawla, Determining the strain rate dependence of cortical and cancellous bones of human tibia using a split Hopkinson pressure bar. International Journal of Crashworthiness, 18(1), pp. 11-18, 2013.

[7] Sun Xiao-Xia, Liu Wei, Impact deformation model of thin-walled shell filled with explosive under high axial shock overload. Applied Mechanics and Materials, 455, pp. 279-285, 2014.

[8] J. O. Hallquist, LS-DYNA theory manual. 2006.

[9] E.L. Lee, C.M. Tarver, Phenomenological model of shock initiation in heterogeneous explosives. Physics of Fluids, 23, pp. 2362-2372, 1980

[10] T. Mukai, H. Kanahashi, Experimental study of energy absorption in a close-celled aluminum foam under dynamic loading. Scripta Materialia, 40(8), pp. 921-927, 1999.

[11] Hu Ming-Hui, Tu Shan-Tung, Strain energy numerical technique for structural damage detection. Applied Mathematics and Computation, 219(5), pp. 2424-2431, 2012. 